\title{
The Design and Actualization of the Vehicle Management in Shandong Juneng Heating Company
}

\author{
Guo Fei ${ }^{1}$, Sun Chengai ${ }^{2}$, Wang Rui ${ }^{2}$, Wang Xiaowen ${ }^{2}$ \\ ${ }^{1}$ The Computing Center of Qingdao Technological University, China Z ZIP 266520 \\ ${ }^{2}$ School of Information of Shandong Science and Technology University, China ZIP 266590 \\ Mailing Address: Guo Fei 2 Changjiang Mid-Road, Qingdao Development Zone \\ Mobile Phone: 13792902182 \\ Email: $\quad$ sun910213@126.com
}

Key words: vehicle management, B/S structure, three-tier structure

\begin{abstract}
The paper, in answering for the actual needs of Shandong Juneng Heating Company, analyses the vehicle management system, constructs the model utilizing UML; designs the database based on the Erwin mechanism and constructs the vehicle management system based on $\mathrm{B} / \mathrm{S}$ model, in which such data as applications, approvals can be edited, statistically analyzed and printed.
\end{abstract}

\section{Functioning analysis}

Shandong Juneng Heating Company is a small-scale company functioning in electric power generation and heat supplying. The Company owns seven subsidiary companies which demands a scientific management of its vehicles. Based on our analysis, a chart for vehicle management system is drawn as follows:

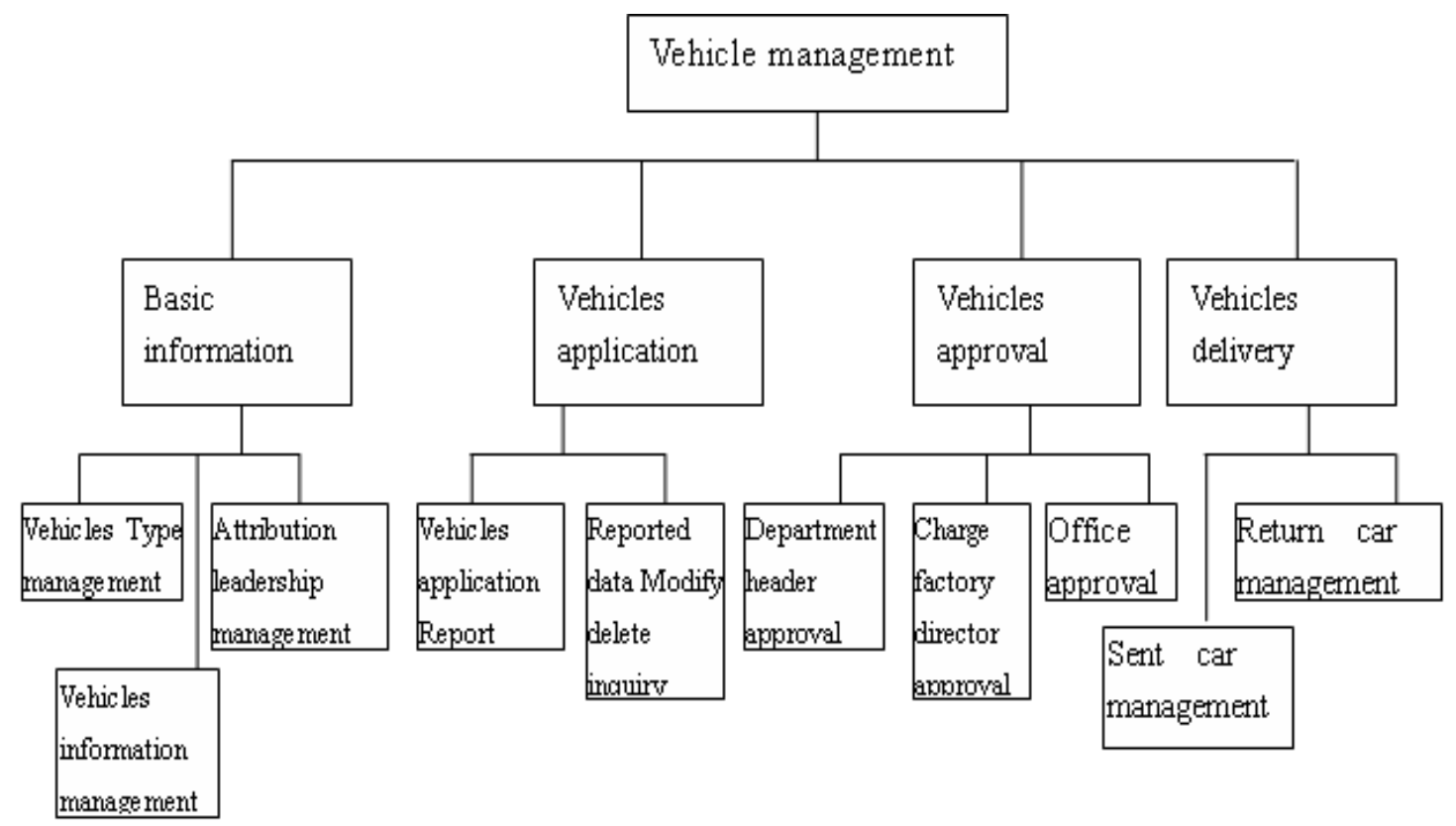

Chart 1 Breakdown of Vehicle Management Functioning

\section{Sample Analysis}

The system comprises four different roles: system administrator, applicants in subsidiary companies, departmental approver, dispatcher and returning person, in which the sample table for the role of administrator is shown in Chart 2, the rest of it looks similar: 


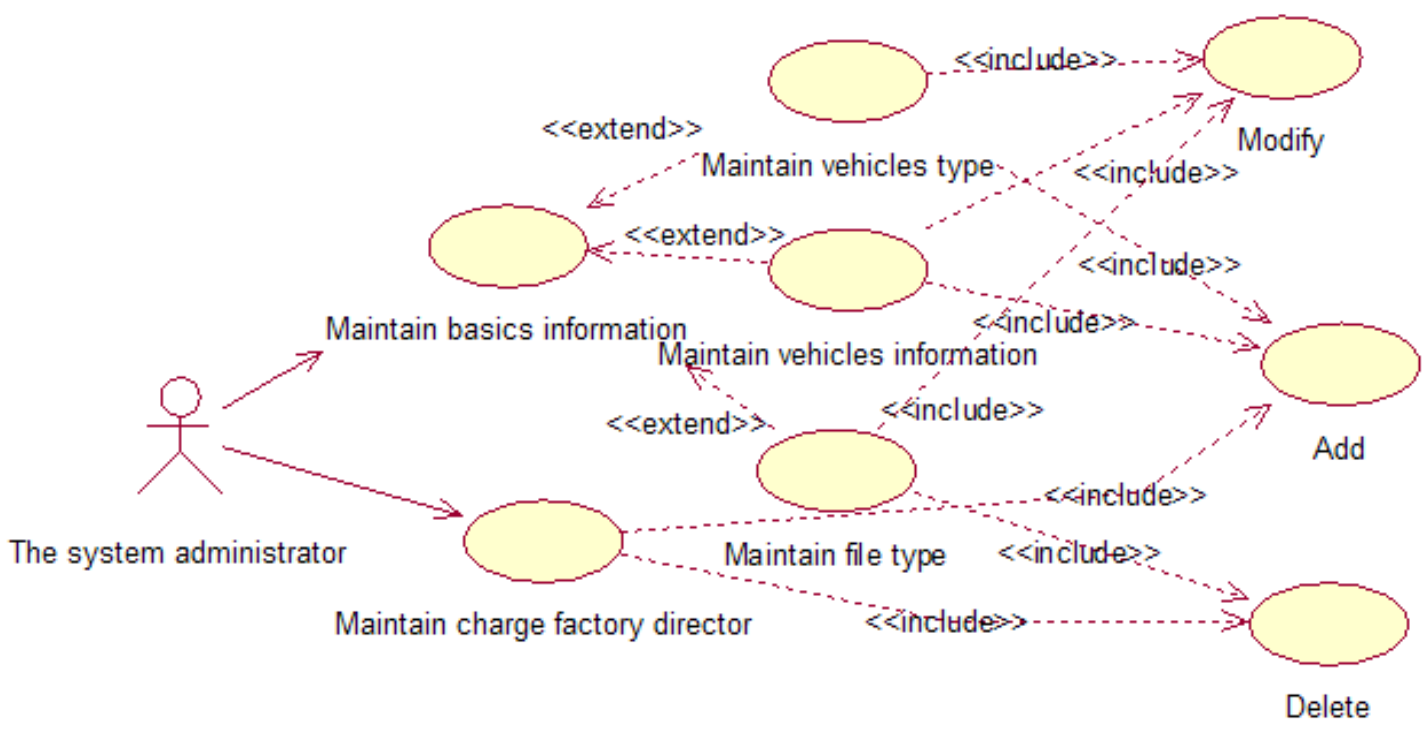

Chart 2 Sample Table for the Role of Administrator

\section{Static Structure Analyses}

Based on the sample model, the static model for vehicle management (i.e. categorical model is abstracted, which is shown in Chart 3

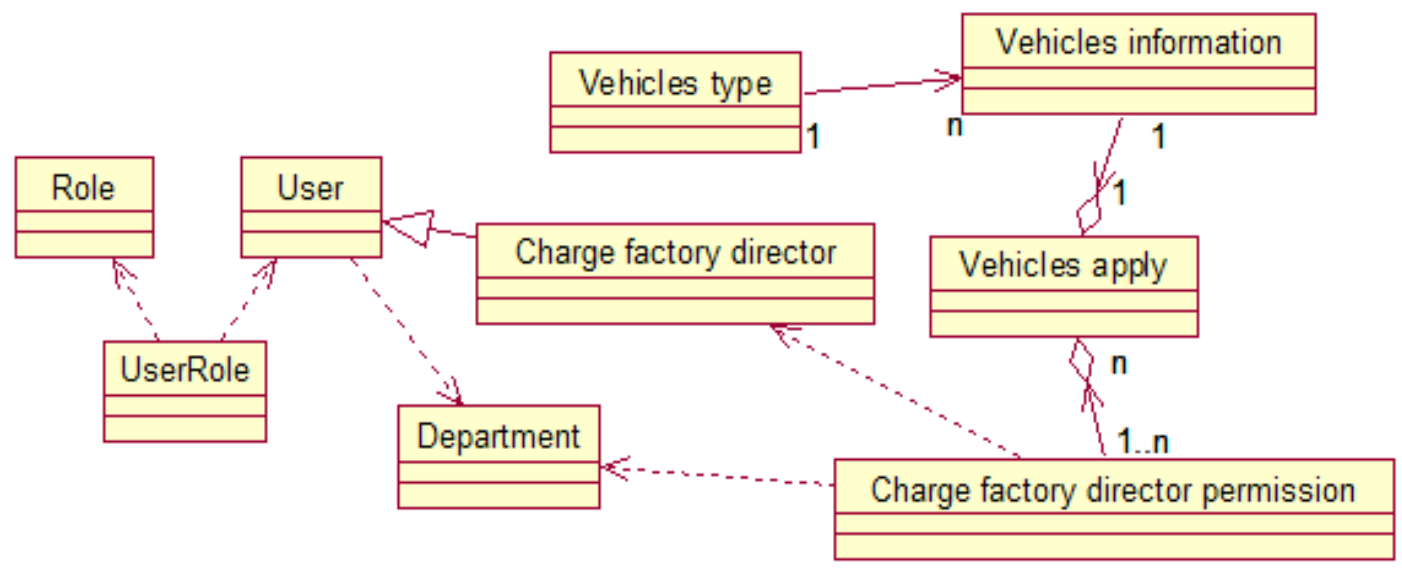

Chart 3 Categorical Model for the System

\section{Dynamic Structure Analyses}

The Vehicle Management System comprises such procedures as application, multi-level approval, dispatching, and returning. After the applicants in the subsidiary companies fill out the application forms, the departmental managers examine and approve these applications, and then the managers of each subsidiary company examine and approve the information approved by the departmental managers; the director of the general office examine and approve the information approved by the subsidiary companies. After the approval from the general office, the vehicle dispatcher sends out the vehicle, in which case the system will prompt the applicant to take the vehicle. Afterwards, the applicants need to return the vehicle after using it to the dispatcher. The specific procedures are shown in Chart 4: 


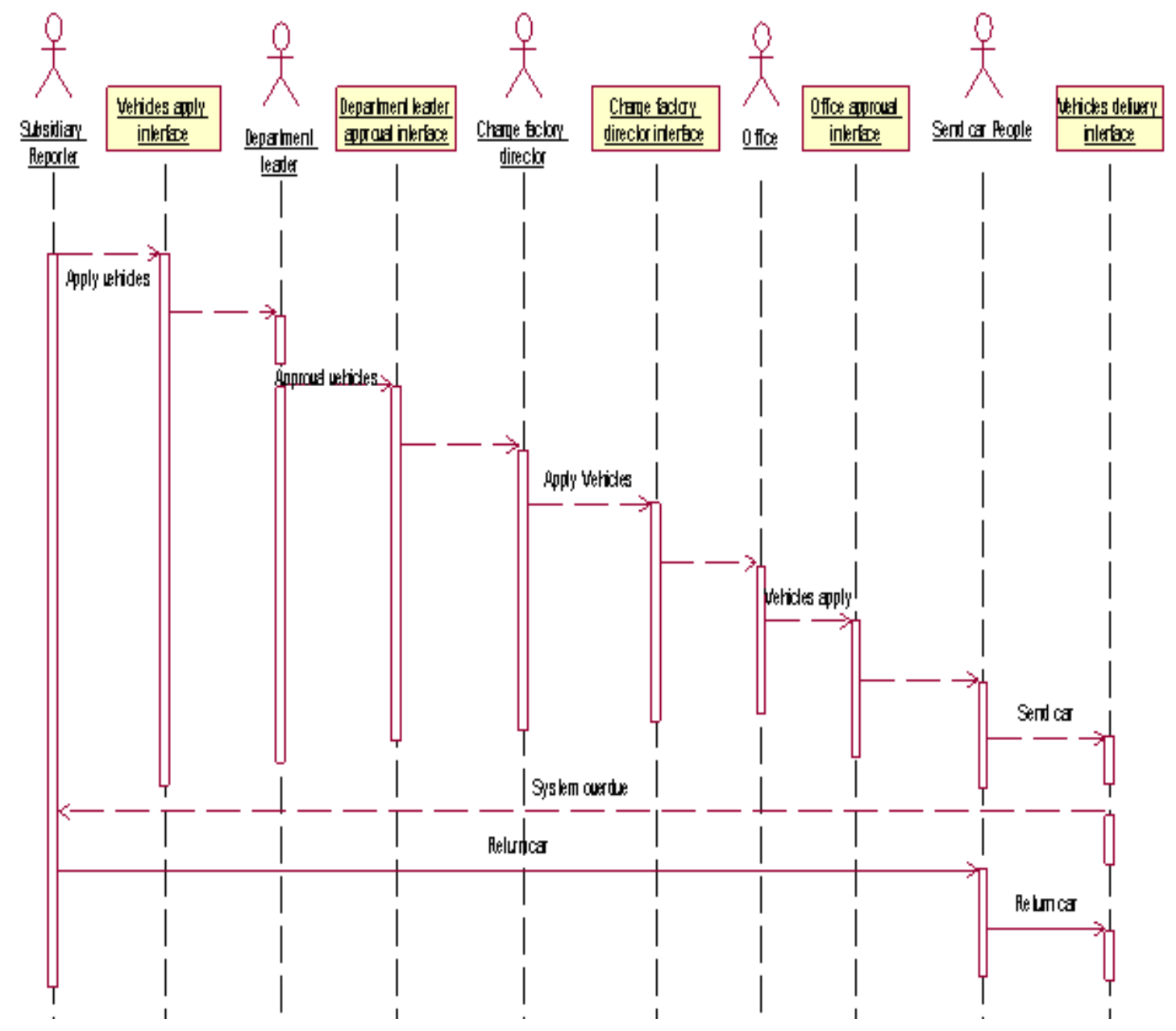

Chart 4 The Procedure of Vehicle Management

\section{Logic Database Design}

Through analysis, the entities involved in the vehicle management system are determined, and the entity-relationship diagram is drawn by utilizing Erwin, which is shown in Chart 5:

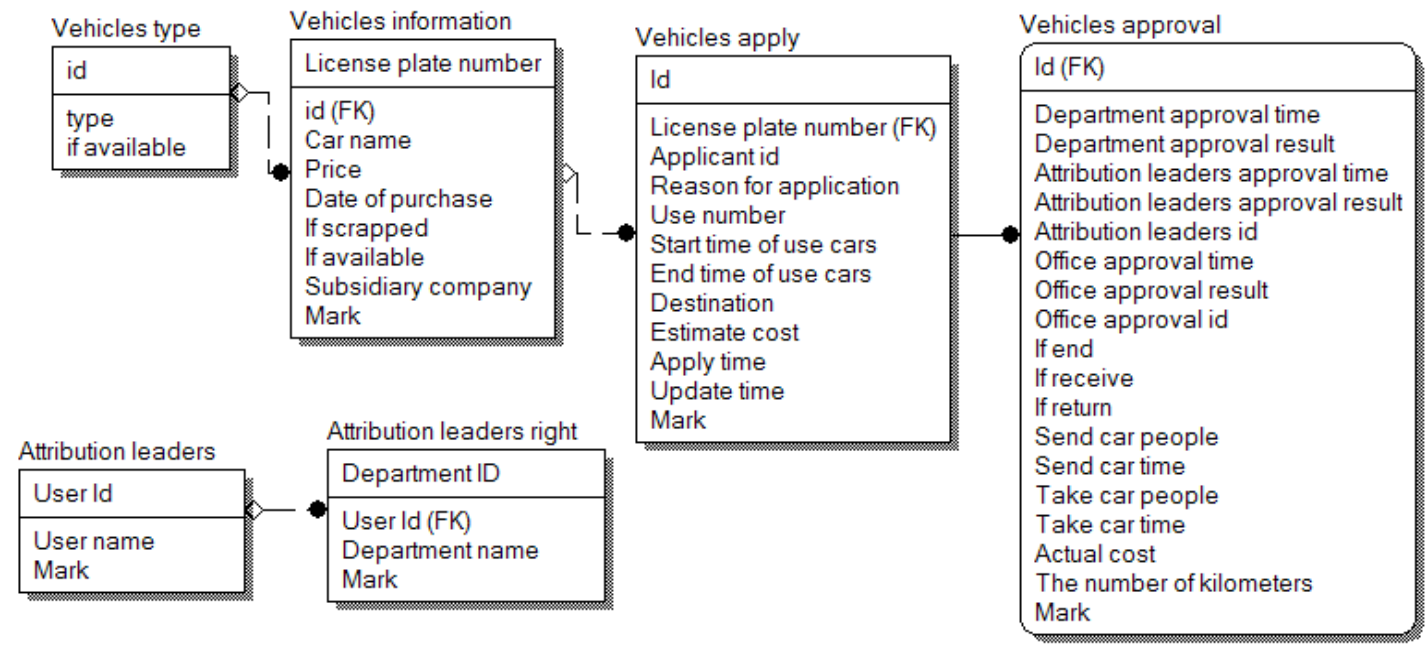

Chart 5 The Entity-relationship Diagram 


\section{Physical Database Design}

Based on the logic model of the database, by using its own data dictionary, and the forward engineering of Erwin, the logic database model can be converted into physical database model, which is shown in Chart 6:

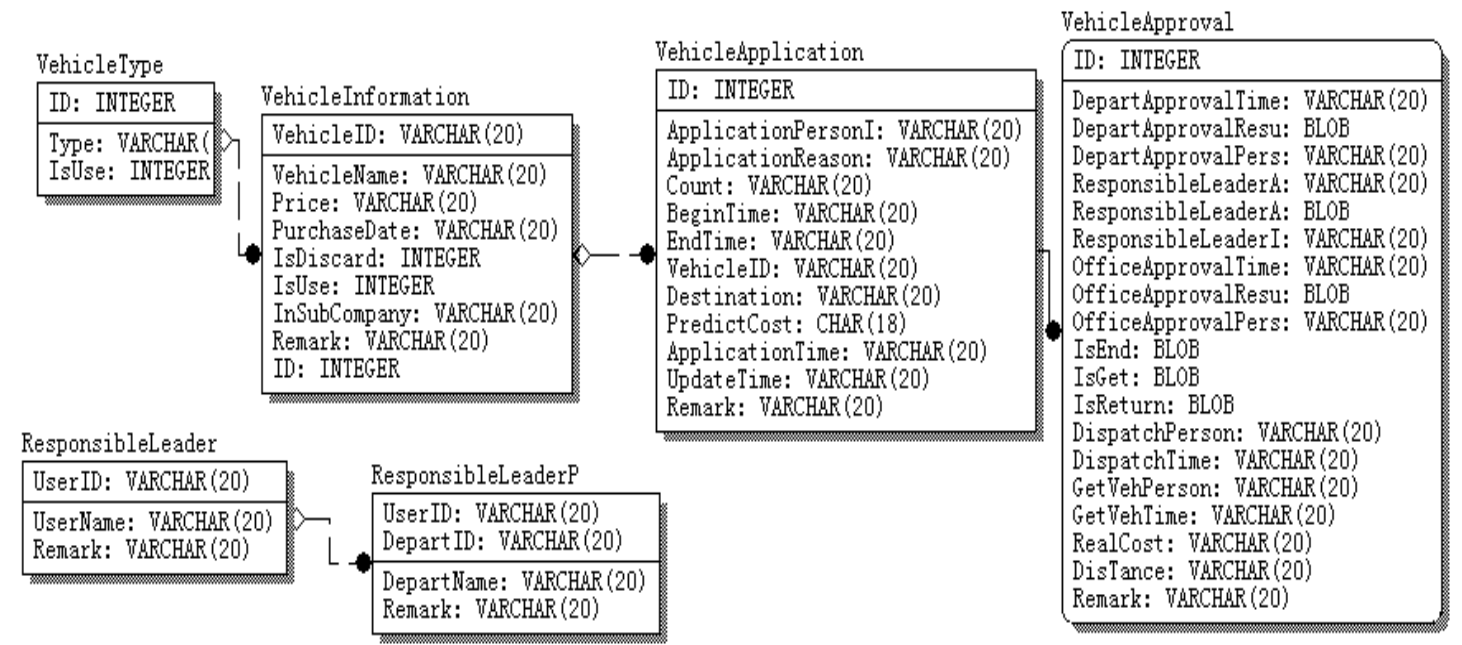

Chart 6: The Physical Model for Vehicle Management

\section{Software System Structure Design}

The system adopts a three-layer structure: presentation layer, business layer, data layer, and designs the software based on B/S model. Under such structure model, the user job interface is actualized through the www browser. A very small part of the job is done at the front-end while most part of the business logic is down at the server, in which case the workload of the user computer is greatly simplified, the cost of system maintenance and updating as well as the workload are significantly reduced. The overall cost of the client is thus reduced.

\section{System Actualization}

The system is developed through .NET platform. The interface of vehicle application is shown in Chart 7. The upper part of the page is for the application for vehicles while the lower part is the management for information modification, deletion, consultation, and examination and approval.

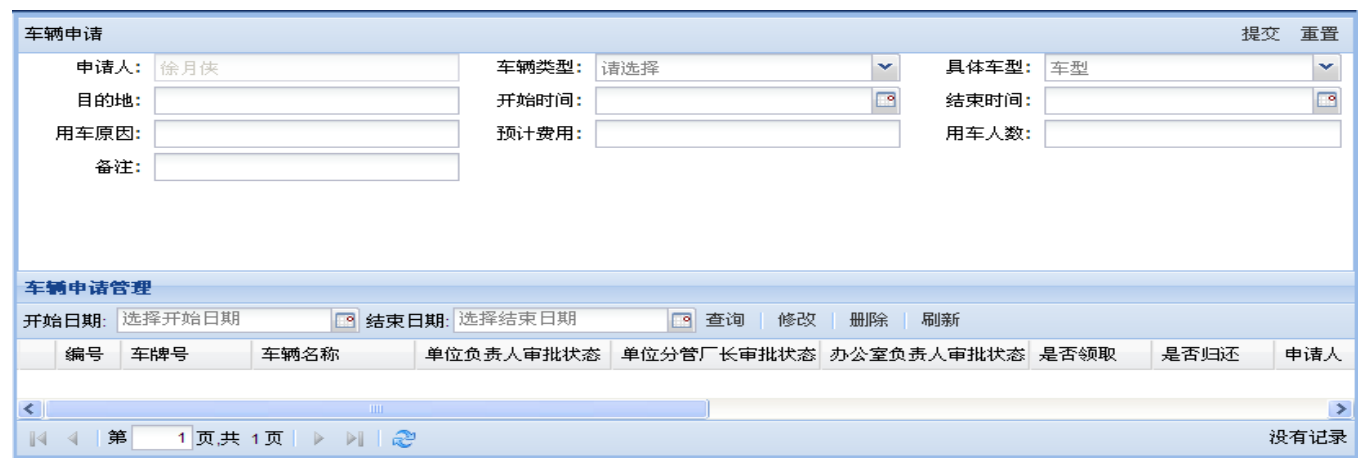

Chart 7 The Interface for Vehicle Application 


\section{Conclusion}

The Vehicle Management System is a sub-system of Shandong Juneng Heating Company. Comprehensive thoughts are given when designed to the server, the database, the application programs, and the users. It is mainly applicable to the $\mathrm{B} / \mathrm{S}$ model. Rigid reference integrity and database structure are being established. The trigger, storage process, constraint, rules and business are integrated into the design of the database, which improves the background management and efficiency, classifies database security to achieve scientific management. The security level of the database is improved, redundant data is reduced. The system has higher data conformity, operability, safety, and thus popularization value.

\section{Reference}

[1] C. Sun, Y. Ren, The Scientific Research Management System for University Schools Based on a Mixed Model J. Fujian Computer 10 (2008) 130-131.

[2] D.Wen, J.Qin, ASP.NET Program Design Basic and Project Training M. People's University of China Publishing House, Beijing 2009.

[3] J. Schmuller, UML Basic and Case M. Translator H. Li, L. Zhao Posts and Telecom Press, Beijing 2007.

[4] S. Sa, S. Wang An Outline of Database System M. Higher Education Press, Beijing 2000.

[5] C. Li, J. Jin, Z. Ping The Principle of Database and Application - Based on SQL Server 2005 M. Tsinghua University, Beijing 2009. 